\title{
Patient responses to swallowing safety cues: A comparison of traditional face-to-face and tele-dysphagia instructional methods
}

\author{
Stacy Gallese Cassel* and Jennifer A McIlvaine \\ Graduate Program in Communication Disorders, School of Health Sciences, Stockton University, USA
}

\begin{abstract}
This investigation compared the outcomes of traditional face-to-face dysphagia intervention to online tele-dysphagia intervention by measuring the correct and incorrect responses to visual and auditory cues presented by a speech-language pathologist. Thirty participants with a confirmed medical condition of dysphagia were randomly assigned into two groups of fifteen, with one group receiving tele-dysphagia intervention and the other traditional face-to-face intervention. Data analysis conducted via t-test indicated that there was no significant difference in the mean scores from tele-dysphagia method ( $\mathrm{M}=9.67$, $\mathrm{SD}=3.74)$ as compared to faceto-face method $(\mathrm{M}=9.00, \mathrm{SD}=2.70), \mathrm{t}(28)=-0.56, \mathrm{p}=0.580$. Additionally, inter-rater reliability scores were obtained by determining a Cohen's kappa coefficient, and revealed a kappa statistic of $\mathrm{k}=1$ for all items, given a $100 \%$ agreement for all trials. Effectiveness measures revealed that $87 \%$ of the tele-dysphagia participants achieved their clinical goal in comparison to $80 \%$ of their face-to-face study counterparts, with tele-dysphagia demonstrating slightly increased effectiveness (7\%). Given that there was no significant statistical difference between the two delivery methods and with inter-rater reliability scores demonstrating perfect agreement, we can suggest that the online tele-dysphagia method can potentially yield effective clinical outcomes similar to a traditional face-to-face method.
\end{abstract}

\section{Introduction}

Aspiration pneumonia is the fifth leading cause of death in Americans over the age of sixty-five, and the third leading cause of death in those over eighty-five [1]. From 2010 to 2030, the elderly population is expected to increase from 39 million to 69 million Americans [2] thus likely increasing the need for dysphagia services. Therapeutic intervention for dysphagia, primarily provided by speech-language pathologists, is an essential part of maintaining both nutritional and respiratory safety while allowing for the quality of life and socialization associated with oral intake.

Given the growing geriatric population and the subsequent increase in the incidence of dysphagia, speech-language pathologists specializing in dysphagia anticipate an ever-increasing role in diagnosis and intervention [3]. In rural and socioeconomically challenged areas; however, access to such intervention remains even more limited due to distance, mobility challenges, and by the unavailability of speechlanguage pathologists to provide dysphagia services [3]. As noted by James Coyle, Ph.D., the number of individuals with dysphagia is quickly exceeding the number of qualified dysphagia therapists [3].

Given this need, there is an emerging body of research dedicated to exploring how telepractice can provide a solution. Telepractice is defined by the American Speech-Language-Hearing Association (ASHA) as "the application of telecommunications technology to deliver professional services at a distance" [4]. ASHA asserts that by allowing clinicians to deliver professional services remotely through the use of telecommunications technology, telepractice has "the potential to extend clinical services to remote, rural, and underserved populations, and to culturally and linguistically diverse populations" [5].

To date, the speech-language pathologist has utilized online telepractice for provision of services in schools, childcare centers, rehabilitation and acute care hospitals, outpatient clinics, universities, corporate settings, and in the home care environment [5], both nationally and internationally. According to the Department of Health and Human Services [1], the two modes of telepractice primarily employed by health care providers include synchronous (real-time interaction between clinician and client/patient that simulate a faceto-face encounter) and asynchronous (the capturing, storing and forwarding of information for professional assessment) methods.

Upon examination of the existing research to determine validity, reliability, and effectiveness, it would seem that telepractice as a service delivery model for speech and language disorders has been well-established in both educational and healthcare settings, both qualitatively and quantitatively [6-15]. In addition, parents, clients, and clinicians involved in these settings report satisfactions with telepractice as a mode of service delivery $[14,16,17]$.

As a result of recent efforts to employ and research the merging of telepractice and dysphagia, the term "tele-dysphagia" has emerged [3]. In cases of tele-dysphagia, also addressed by speech-language pathologists, formal research continues its efforts to establish a theoretical base, although the focus has been on assessment rather than

Correspondence to: Stacy Gallese Cassel, Director, Graduate Program of Communication Disorders, Stockton University, School of Health Sciences, 101 Vera King Farris Drive, Galloway, New Jersey 08201, USA; Tel: (610) 213-6818; E-mail: stacy.cassel@stockton.edu

Key words: tele-dysphagia, telepractice, dysphagia, deglutition, deglutition disorders

Received: October 30, 2017; Accepted: November 27, 2017; Published: December 01, 2017 
intervention [18-21] and adults rather than pediatrics [22]. To date, research in tele-dysphagia can essentially be categorized according to the following areas: clinical tele-dysphagia assessment [20,21,23,24] videofluoroscopic swallowing studies $[18,19,25,26]$ and tele-dysphagia intervention [22,27-31].

Although the above studies lend credibility to the use of telepractice for dysphagia assessment, minimal quantifiable studies currently exist in validating dysphagia intervention via telepractice. To date, six studies exist-four examining the use of tele-dysphagia for the treatment of head and neck cancer $[27,28,30,31]$ and two determining the feasibility of a pediatric tele-dysphagia program [22,29].

This investigation was proposed and initiated subsequent to a review of the literature establishing two primary considerations: 1) a clearly defined need for tele-dysphagia services given projected geriatric and dysphagic population trends; and, 2) limited research determining the effectiveness of tele-dysphagia intervention. Previous studies indicate successful efforts to validate the use of face-to-face dysphagia intervention, and some preliminary efforts to validate teledysphagia assessment. Tele-dysphagia intervention research efforts; however, have been limited. The investigation serves to expand this knowledge base via a comparison of participant ability to achieve the goal of swallowing strategy acquisition in a clinical session given two different modes of service delivery-traditional face-to-face intervention and tele-dysphagia.

\section{Methods}

Thirty participants contributed to the parallel study upon meeting the following criteria: adult with a confirmed medical diagnosis of cerebrovascular accident (CVA) or traumatic brain injury (TBI) with positive findings according to computed tomography (CT Scan) or magnetic resonance imaging (MRI) of the brain. Participants further had a confirmed medical diagnosis of dysphagia after receiving a Videofluoroscopic Swallowing Study (VFSS). Once a potential participant was identified, the informed consent process began with an orientation session involving the candidate, which was designed to determine his/her interest by providing a step-by-step description of the intervention session conducted via tele-dysphagia versus faceto-face methods and, if interest was verbally expressed the informed consent form was reviewed.

In order to ensure each participant was fully competent to consent and was aware of all benefits and risks pertaining to the study, the following scores on the National Outcomes Measurement System (NOMS) / Functional Communication Measurement (FCM) were necessary: level 5 for attention, level 4-6 for memory, level 5-6 for language comprehension and level 4-5 for swallowing [4]. These scores indicated that participants could maintain functional attention task, comprehend basic verbal language, recall and repeat directions, and demonstrate a level of swallowing function that could benefit from intervention. Lastly, full motoric independence with feeding at ninety degrees trunk flexion, seated at a table was required.

Based on the availability of willing participants at the facility and subsequent to participant selection and consent, a sample size of 30 was attained via a convenience sample. All 30 participants originally considered by the investigators consented to participate and thus were assigned a referential number and were referred exclusively by that number during medical chart review, data collection, analysis, and report of findings. Once participant consent was acquired, each of the 30 participants were randomly assigned to therapy in either the control group via face-to-face methods or the study group via tele-dysphagia format by the principal investigator. Upon selection, placement into each group was alternated at a 1:1 ratio until each group had 15 participants.

Following the format outlined in Figure 1, each participant engaged in a dysphagia therapy session targeting the first fifteen oral intake trials in either the face-to-face or tele-dysphagia format following their random assignment into each group. To accomplish this, participants were provided with visual and auditory cues during a task-oriented mealtime activity, which targeted the independent use of a swallowing safety strategy.

Cues were incorporated into our research as ASHA lends objective support to its contention that the use of cueing systems is a crucial component of dysphagia intervention success, as determined by a decrease in the occurrence of aspiration in dysphagia populations [32]. Therefore, employing the use of cueing systems is seemingly beneficial in its effort to maximize the respiratory safety of individuals with dysphagia while maintaining nutrition and quality of life.

Each session addressed one of the following strategies: chin down posture, cyclic ingestion compensation, head turn posture, or bolus size regulations, as determined to be clinically effective via initial clinical dysphagia assessment. The chin down/chin tuck position requires the patient to direct the chin toward the chest prior to swallowing the bolus to facilitate clearing of food residuals in the vallecular space and to more adequately protect the airway from bolus entry. Head turn position requires the patient to turn the head/neck to either the left or right side prior to swallowing the bolus. In the case of hemiparesis secondary to CVA, turning the head toward the weaker side has been shown to direct the bolus through the pharynx via the stronger side of the swallowing mechanism, hence minimizing the risk of entrance into the airway [33]. Cyclic ingestion requires the patient to alternate the intake of solids and liquids at prescribed intervals with the intention of clearing the pharyngeal residuals at risk of entering the airway and facilitating improved bolus transit through the esophagus [33]. Lastly, bolus size alteration/regulation requires the patient to independently regulate the size of the bolus to a specific amount, or to self-feed at a slower rate during feeding in order to maximize swallowing safety [33].

The risk of aspiration during eating for participants, was a risk projected to be reduced during therapy sessions, since dysphagia intervention and the use of safety strategies have been determined to significantly decrease the likelihood of aspiration while facilitating improved swallowing safety [32]. These strategies were predetermined to be beneficial to the patient via clinical assessment, which is the long-standing method for strategy selection [34]. Should any concerns about subject safety arise, they would be immediately addressed by the attending medical staff, as is standard site protocol for all therapy sessions.

The specific swallowing strategy that was determined for each participant was included in the following clinical goal consistent with the practice of dysphagia intervention [5]:

Following clinical instruction, the participant will demonstrate the targeted swallowing strategy given gradually fading visual and auditory cues with greater than or equal to $80 \%$ accuracy (12 of 15 trials).

Fifteen oral intake trials were assessed as this was the minimum number of trials achieved by each participant. It is this goal that became the focus of each intervention session, with the subsequent collection of data in order to determine whether the goal was achieved. 


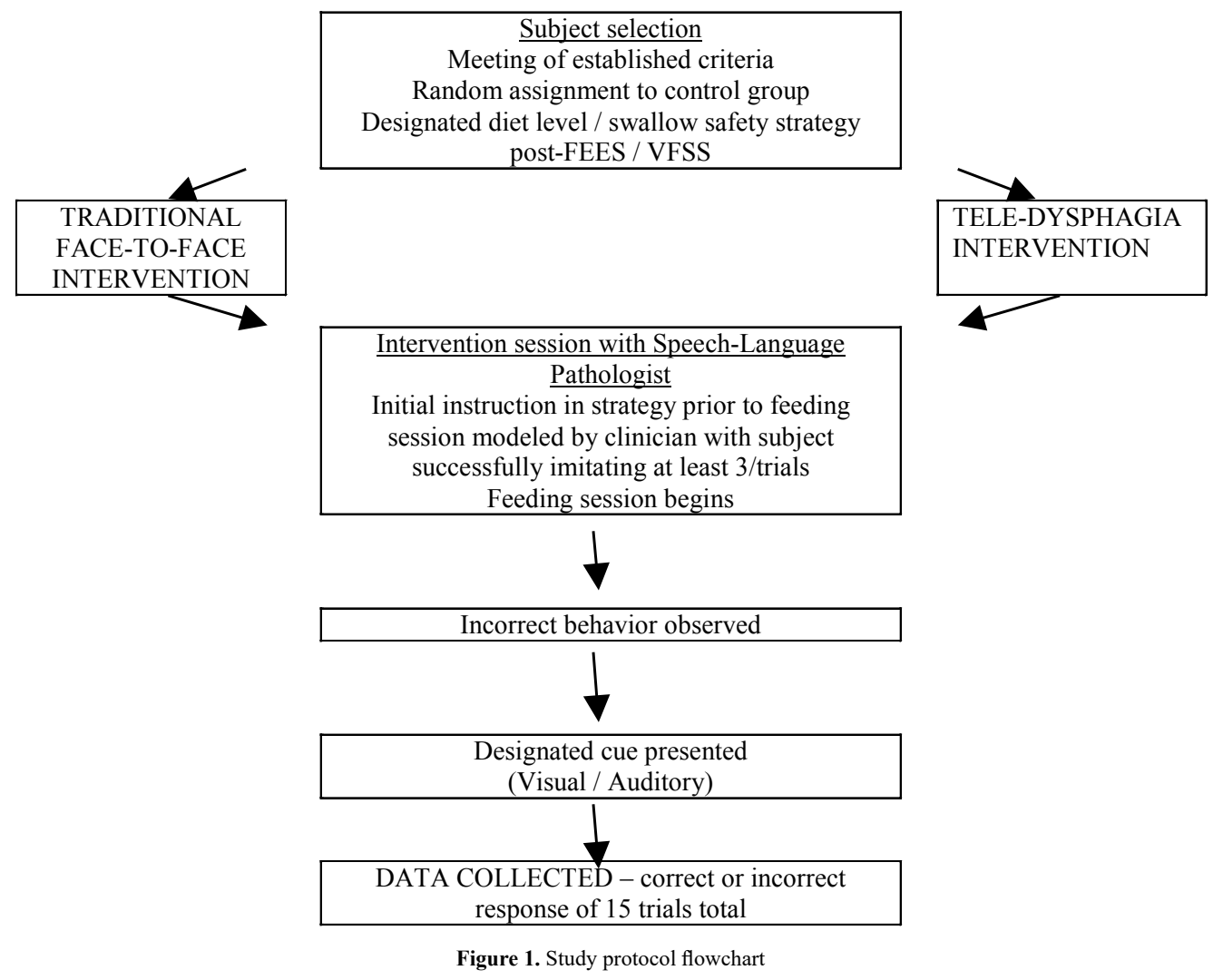

The investigation was conducted in a designated therapy area of a sub-acute/ long-term medical center, featuring the clinician in either the face-to-face or tele-dysphagia format. Each participant was seen for only one session following a brief training period to finalize candidacy, thus no follow up was initiated. Sessions were conducted by two certified speech-language pathologists-the principal investigator and an attending speech-language pathologist. All sessions were recorded and viewed by a third certified speech-language pathologist for inter-rater reliability. In the face-to-face setting, the clinician was present in the therapy room, seated approximately three feet directly across from the participant in the therapy room during the participant's snack or mealtime. The food tray from which the participant self-fed was at a distance necessary for independent oral intake, which was approximately three to six inches from the seated edge of the table.

Each trial tele-dysphagia session was conducted between the clinician and the participant targeting their specific swallowing strategy using the Macintosh FaceTime videoconferencing system to allow for a real-time interaction, as well as VSee, a HIPAA-compliant, encrypted telehealth application that ensured participant confidentiality [35]. The participants were given a brief orientation to the equipment upon which they were required to demonstrate sufficient ability to see and hear the video / audio signal and respond to commands. In the tele-dysphagia setting, the clinician was located in a remote site, interacting with the participant via Facetime/Vsee video conferencing applications. The participant was seated three feet directly across from a twenty-one-inch computer screen, which allowed for two-way video/ audio communication, with the same food setup as their face-to-face study counterparts.

In both settings, the primary medical personnel were present throughout the session to ensure the safety of the participant; with immediate intervention on standby should any concerns arise. In the course of the investigation, no participants were observed to have respiratory distress in the course of the session; additionally, all participants were reported by the primary medical staff to have unchanged, stable respiratory status.

\section{Results}

A total of thirty participants were recruited between July 2014 and December of 2014. Of the fifteen participants randomly assigned to receive tele-dysphagia intervention and the fifteen participants randomly assigned to receive face-to-face intervention, all were able to tolerate the entire session to which they were assigned. The length of each session was varied depending on the intake rate of the particular participant with a range of 25 to 65 minutes; however, only the first 15 trials were used as data to ensure reliability. 15 oral intake trials were assessed as this was the minimum number of trials achieved by each participant. The session concluded after the intake (meal).

A mixed-design analysis of variance was conducted to examine if there were main effects of cue, gender, delivery type, etiology, or age on participant responses (and/or interaction effects) among them. The cue was treated as a within-subject (repeated) factor with two categories (with cues and without cues) as each participant's outcome was repeatedly measured both with cues and without cues. On the other hand, the remaining variables (gender, delivery type, etiology, and age) were treated as between-subject factors with two categories each; specifically, (a) gender (female vs. male), (b) delivery type (teledysphagia versus face-to-face), (c) etiology (CVA vs. TBI), and (d) age ( $<70$ versus $\geq 70$ years old).

As shown in Table 1, the results indicated there was a significant within-subject effect of cues 
Table 1. Result of mixed-design analysis of variance

\begin{tabular}{|c|c|c|c|}
\hline Source & df & F & p \\
\hline Cues & 29 & 14.99 & 0.001 \\
\hline (a) Gender & 25 & 0.07 & 0.8 \\
\hline (b) Delivery & 25 & 1.36 & 0.26 \\
\hline (c) Etiology & 25 & 0.38 & 0.54 \\
\hline (d) Age & 25 & 0.49 & 0.49 \\
\hline df $=$ denominator degrees of freedom & & \\
\hline
\end{tabular}

$(\mathrm{F}(1,29)=14.99, \mathrm{p}=0.001)$ on participant responses. However, there were no significant main effects of between-subject factors (gender, delivery type, etiology, or age) on participant responses. To ensure that the effect of cues did not interact with the between-subject factors, two-way interaction effects were additionally tested. There were no interaction effects between cues and any of the four factors with respect to participant responses.

In order to determine if tele-dysphagia as a service delivery method demonstrated a significant difference when compared to a traditional face-to-face method (with respect to services given with cues or without cues) two independent t-tests were conducted. First, a t-test was conducted by treating a total score to the services with cues as a dependent variable and a service delivery method as an independent variable with two categories: tele-dysphagia ( $\mathrm{n}=15$; study group) or face-to-face ( $\mathrm{n}=15$; control group). As shown in Table 2 , the result suggested that there was no significant difference in the mean scores from tele-dysphagia method $(\mathrm{M}=9.67, \mathrm{SD}=3.74)$ as compared to faceto-face method $(\mathrm{M}=9.00, \mathrm{SD}=2.70), \mathrm{t}(28)=-0.56, \mathrm{p}=0.580)$.

Second, another t-test was conducted by treating a total score to the services without cues as a dependent variable and a service delivery method as an independent variable with the two categories (Table 2). Similar to above, it was found that there was no significant difference in the mean scores from tele-dysphagia method $(\mathrm{M}=3.93, \mathrm{SD}=4.65)$ as compared to face-to-face method $(\mathrm{M}=4.20, \mathrm{SD}=4.13), \mathrm{t}(28)=0.17$, $\mathrm{p}=0.870$ ). Similarly, there were no differences due to gender (Table 3 ) or injury type (Table 4 ) in the participant responses (regardless of the use of cues or not). Tables 5-8 indicate that there was no effect of gender or injury type either within the FTF group or within the tele-dysphagia group.

Next, we examined if there was any difference between services provided with cues and without cues with respect to participant responses. For this, we conducted a dependent sample t-test; we treated a total score of participant responses as a dependent variable and the use or absence of cues as an independent variable with the two categories 'with cues' and 'without cues.' Findings shown in Table 9 indicate that the mean scores to services provided with cues lead to significantly greater outcomes than the services without cues.

Inter-rater reliability was determined for each individual item (given a 0/1 score to indicate a positive or negative response, with or without cues) via a Cohen's kappa coefficient [36] in order to measure the degree of agreement between the two raters. Findings indicated a kappa statistic of $\mathrm{k}=1$ for all items, given a $100 \%$ agreement for all trials.

In the tele-dysphagia group when using cues among the 15 trials in total, all participants demonstrated positive responses with cues at least 3 times, as shown in Table 10. Four participants (26.7\%) showed positive responses 13 out of 15 times most often. Table 11 indicates that when cues were not used, seven participants (46.7\%) showed no (or negative) responses most often.

For the face-to-face group, when using cues, among the 15 trials in total, all 15 participants showed their positive responses at least 4 times. As shown in Table 12, participants showed the positive responses $6(20 \%), 9(20 \%)$, and $11(20 \%)$ out of 15 times most often. When cues were not used, as displayed in Table 13, seven participants $(33.3 \%)$ showed no (or negative) responses most often.

Given the 30 participants, $87 \%$ of the tele-dysphagia participants achieved their clinical goal $(>=80 \%)$, while $80 \%$ of the face-to-face participants achieved this goal. As illustrated in Table 14 and 15, both modes of service delivery facilitated effective and successful outcomes, with tele-dysphagia demonstrating slightly increased effectiveness (7\%).

\section{Discussion}

The results of independent t-tests comparing face-to-face and teledysphagia delivery modes did not demonstrate a significant statistical difference. These results provide validation for the use of tele-dysphagia services in cases where face-to-face dysphagia intervention is not an option due to factors such as mobility or distance - though it should be noted that these results are limited to the specific safety strategies investigated.

Table 2. Independent t-tests comparing treatment and control groups $(n=30)$

\begin{tabular}{|c|c|c|c|c|c|c|}
\hline \multirow[b]{2}{*}{ Score } & \multicolumn{2}{|c|}{ Face-to-face $(n=15)$} & \multicolumn{2}{|c|}{ Tele-Dysphagia $(n=15)$} & \multirow[b]{2}{*}{$\mathrm{t}$} & \multirow[b]{2}{*}{$\mathrm{p}$} \\
\hline & M & SD & M & SD & & \\
\hline With Cues & 9.00 & 2.7 & 9.67 & 3.74 & -0.56 & 0.580 \\
\hline $\begin{array}{l}\text { Without } \\
\text { Cues }\end{array}$ & 4.20 & 4.13 & 3.93 & 4.65 & 0.17 & 0.870 \\
\hline \multicolumn{7}{|c|}{$\mathrm{df}=28$ for both tests } \\
\hline
\end{tabular}

Table 3. Independent t-tests comparing gender difference $(n=30)$

\begin{tabular}{|c|c|c|c|c|c|c|}
\hline & \multicolumn{2}{|c|}{ Female (n=18) } & \multicolumn{2}{|c|}{ Male (n=12) } & & \\
\hline Score & $\mathrm{M}$ & $\mathrm{SD}$ & $\mathrm{M}$ & $\mathrm{SD}$ & $\mathrm{t}$ & $\mathrm{p}$ \\
\hline With Cues & 9.78 & 3.47 & 8.67 & 2.8 & 0.92 & 0.364 \\
\hline $\begin{array}{c}\text { Without } \\
\text { Cues }\end{array}$ & 3.39 & 4.51 & 5.08 & 3.98 & -1.05 & 0.301 \\
\hline
\end{tabular}

Table 4. Independent t-tests comparing injury types $(n=30)$

\begin{tabular}{|c|c|c|c|c|c|c|}
\hline & \multicolumn{2}{|c|}{ CVA (n=21) } & \multicolumn{2}{c|}{ TBI (n=9) } & & \\
\hline Score & M & SD & M & SD & t & p \\
\hline With Cues & 9.48 & 3.28 & 9 & 3.24 & 0.37 & 0.717 \\
\hline $\begin{array}{c}\text { Without } \\
\text { Cues }\end{array}$ & 3.9 & 4.36 & 4.44 & 4.48 & -0.31 & 0.76 \\
\hline
\end{tabular}

Table 5. Independent $\mathrm{t}$-tests comparing gender difference within FTF group $(\mathrm{n}=15)$

\begin{tabular}{|c|c|c|c|c|c|c|}
\hline & \multicolumn{2}{|c|}{ Female (n=9) } & \multicolumn{2}{|c|}{ Male (n=6) } & & \\
\hline Score & M & SD & M & SD & t & p \\
\hline With Cues & 9.22 & 3.23 & 8.67 & 1.86 & 0.38 & 0.711 \\
\hline $\begin{array}{c}\text { Without } \\
\text { Cues }\end{array}$ & 3.56 & 4.67 & 5.17 & 3.31 & -0.73 & 0.479 \\
\hline
\end{tabular}

Table 6. Independent t-tests comparing gender difference within tele-dysphagia group (n $=15$ )

\begin{tabular}{|c|c|c|c|c|c|c|}
\hline & \multicolumn{2}{|c|}{ Female (n=9) } & \multicolumn{2}{c|}{ Male (n=6) } & & \\
\hline Score & M & SD & M & SD & t & p \\
\hline With Cues & 10.33 & 3.81 & 8.67 & 3.72 & 0.84 & 0.417 \\
\hline $\begin{array}{c}\text { Without } \\
\text { Cues }\end{array}$ & 3.22 & 4.63 & 5 & 4.9 & -0.71 & 0.489 \\
\hline
\end{tabular}

Table 7. Independent t-tests comparing injury types within FTF group $(n=15)$.

\begin{tabular}{|c|c|c|c|c|c|c|}
\hline & \multicolumn{2}{|c|}{ CVA (n= 12) } & \multicolumn{2}{|c|}{ TBI (n=3) } & & \\
\hline Score & M & SD & M & SD & t & p \\
\hline With Cues & 9.33 & 2.81 & 7.67 & 2.08 & 0.95 & 0.358 \\
\hline $\begin{array}{c}\text { Without } \\
\text { Cues }\end{array}$ & 3.58 & 4.2 & 6.67 & 3.21 & -1.17 & 0.262 \\
\hline
\end{tabular}


The results of the mixed-design analysis of variance shown in Table 1 indicate that there were no significant main effects of between-subject factors on participant responses regardless of delivery mode. In an examination of the data, one can conclude that both tele-dysphagia and face-to-face modes of service delivery can provide comparable clinical results regardless of participant gender, age, or etiology.

Conversely, the mixed-design analysis of variance demonstrated a high within-subject effect when a comparison was made between services provided with and without cues, in both face-to-face and tele-dysphagia delivery modes. The cue is treated as a within-subject (repeated) factor with two categories (with cues and without cues) as

Table 8. Independent t-tests comparing injury types within tele-dysphagia group $(n=15)$

\begin{tabular}{|c|c|c|c|c|c|c|}
\hline & \multicolumn{2}{|c|}{ CVA (n=9) } & \multicolumn{2}{c|}{ TBI (n=6) } & & \\
\hline Score & M & SD & M & SD & t & p \\
\hline With Cues & 9.67 & 4 & 9.67 & 3.67 & 0 & 1 \\
\hline $\begin{array}{c}\text { Without } \\
\text { Cues }\end{array}$ & 4.33 & 4.77 & 3.33 & 4.84 & 0.4 & 0.7 \\
\hline
\end{tabular}

Table 9. Paired t-test comparing service delivery types $(n=30)$

\begin{tabular}{|c|c|c|c|c|c|}
\hline \multicolumn{2}{|c|}{ With Cues } & \multicolumn{2}{c|}{ Without Cues } & & \\
\hline $\mathrm{M}$ & $\mathrm{SD}$ & $\mathrm{M}$ & $\mathrm{SD}$ & $\mathrm{t}$ & $\mathrm{p}$ \\
\hline 9.33 & 3.22 & 4.07 & 4.32 & $3.87 * * *$ & 0.001 \\
\hline $\mathrm{df}=29 ; * * *=\mathrm{p} \leq .001$ & & & & \\
\hline
\end{tabular}

Table 10. Measures of effectiveness: tele-dysphagia with cues

\begin{tabular}{|c|c|c|c|c|c|}
\hline \multicolumn{7}{|c|}{ Participant Responses with Cues } \\
\hline \multirow{3}{*}{ Positive responses } & $\begin{array}{c}\text { Number of } \\
\text { participants }\end{array}$ & Percent & $\begin{array}{c}\text { Valid } \\
\text { Percent }\end{array}$ & $\begin{array}{c}\text { Cumulative } \\
\text { Percent }\end{array}$ \\
\hline \multirow{4}{*}{ Valid } & 3 & 2 & 13.3 & 13.3 & 13.3 \\
\cline { 2 - 6 } & 6 & 2 & 13.3 & 13.3 & 26.7 \\
\cline { 2 - 6 } & 8 & 2 & 13.3 & 13.3 & 40 \\
\cline { 2 - 6 } & 11 & 3 & 20 & 20 & 60 \\
\cline { 2 - 6 } & 12 & 1 & 6.7 & 6.7 & 66.7 \\
\cline { 2 - 6 } & 13 & 4 & 26.7 & 26.7 & 93.3 \\
\cline { 2 - 6 } & 14 & 1 & 6.7 & 6.7 & 100 \\
\cline { 2 - 6 } & Total & 15 & 100 & 100 & - \\
\hline
\end{tabular}

Table 11. Measures of effectiveness: tele-dysphagia without cues

\begin{tabular}{|c|c|c|c|c|c|}
\hline \multicolumn{6}{|c|}{ Participant Responses without Cues } \\
\hline \multirow{2}{*}{ Positive responses } & $\begin{array}{c}\text { Number of } \\
\text { participants }\end{array}$ & Percent & $\begin{array}{c}\text { Valid } \\
\text { Percent }\end{array}$ & $\begin{array}{c}\text { Cumulative } \\
\text { Percent }\end{array}$ \\
\hline \multirow{4}{*}{ Valid } & 0 & 7 & 46.7 & 46.7 & 46.7 \\
\cline { 2 - 6 } & 2 & 1 & 6.7 & 6.7 & 53.3 \\
\cline { 2 - 6 } & 3 & 1 & 6.7 & 6.7 & 60 \\
\cline { 2 - 6 } & 6 & 2 & 13.3 & 13.3 & 73.3 \\
\cline { 2 - 7 } & 9 & 2 & 13.3 & 13.3 & 86.7 \\
\cline { 2 - 7 } & 12 & 2 & 13.3 & 13.3 & 100 \\
\cline { 2 - 7 } & Total & 15 & 100 & 100 & - \\
\hline
\end{tabular}

Table 12. Measures of effectiveness: face-to-face with cues

\begin{tabular}{|c|c|c|c|c|c|}
\hline \multicolumn{6}{|c|}{ Participant Responses with Cues } \\
\hline \multirow{2}{*}{ Positive responses } & $\begin{array}{c}\text { Number of } \\
\text { participants }\end{array}$ & Percent & $\begin{array}{c}\text { Valid } \\
\text { Percent }\end{array}$ & $\begin{array}{c}\text { Cumulative } \\
\text { Percent }\end{array}$ \\
\hline \multirow{4}{*}{ Valid } & 4 & 1 & 6.7 & 6.7 & 6.7 \\
\cline { 2 - 7 } & 6 & 3 & 20 & 20 & 26.7 \\
\cline { 2 - 7 } & 7 & 1 & 6.7 & 6.7 & 33.3 \\
\hline & 9 & 3 & 20 & 20 & 53.3 \\
\cline { 2 - 7 } & 10 & 2 & 13.3 & 13.3 & 66.7 \\
\cline { 2 - 7 } & 11 & 3 & 20 & 20 & 86.7 \\
\cline { 2 - 7 } & 13 & 2 & 13.3 & 13.3 & 100 \\
\hline & Total & 15 & 100 & 100 & - \\
\hline
\end{tabular}

Table 13. Measures of effectiveness: face-to-face without cues

\begin{tabular}{|c|c|c|c|c|c|}
\hline \multicolumn{6}{|c|}{ Participant Responses without Cues } \\
\hline \multicolumn{2}{|c|}{ Positive responses } & $\begin{array}{l}\text { Number of } \\
\text { participants }\end{array}$ & Percent & $\begin{array}{c}\text { Valid } \\
\text { Percent }\end{array}$ & $\begin{array}{l}\text { Cumulative } \\
\text { Percent }\end{array}$ \\
\hline \multirow{10}{*}{ Valid } & 0 & 5 & 33.3 & 33.3 & 33.3 \\
\hline & 1 & 1 & 6.7 & 6.7 & 40 \\
\hline & 2 & 1 & 6.7 & 6.7 & 46.7 \\
\hline & 3 & 1 & 6.7 & 6.7 & 53.3 \\
\hline & 5 & 1 & 6.7 & 6.7 & 60 \\
\hline & 6 & 1 & 6.7 & 6.7 & 66.7 \\
\hline & 8 & 1 & 6.7 & 6.7 & 73.3 \\
\hline & 9 & 3 & 20 & 20 & 93.3 \\
\hline & 11 & 1 & 6.7 & 6.7 & 100 \\
\hline & Total & 15 & 100 & 100 & - \\
\hline
\end{tabular}

Table 14. Achievement of clinical goal, tele-dysphagia participants ( $87 \%$ achieved goal)

\begin{tabular}{|c|c|c|}
\hline Participant \# & $\begin{array}{c}\text { Goal achieved }(>=12 \text { of } \mathbf{1 5} \\
\text { trials) }\end{array}$ & Goal not achieved \\
\cline { 3 - 3 }$(<12$ trials $)$
\end{tabular}

Table 15. Achievement of clinical goal, face-to-face participants ( $80 \%$ achieved goal)

\begin{tabular}{|c|c|c|}
\hline Participant \# & $\begin{array}{c}\text { Goal achieved (>=12 of 15 } \\
\text { trials) }\end{array}$ & Goal not achieved \\
\cline { 3 - 3 }$(<12$ trials $)$ \\
\hline 3 & 15 of 15 & - \\
\hline 5 & 13 of 15 & - \\
\hline 7 & 13 of 15 & - \\
\hline 9 & 15 of 15 & - \\
\hline 11 & - & 11 of 15 \\
\hline 13 & - & 9 of 15 \\
\hline 15 & 12 of 15 & - \\
\hline 17 & 12 of 15 & - \\
\hline 19 & 15 of 15 & - \\
\hline 21 & 15 of 15 & - \\
\hline 23 & 15 of 15 & - \\
\hline 25 & 13 of 15 & - \\
\hline 27 & 14 of 15 & - \\
\hline 29 & 15 of 15 & 11 of 15 \\
\hline
\end{tabular}

each participant's outcome was repeatedly measured both with cues and without cues. In the within-subject design, studying multiple outcomes (15 trials) for each participant allows each participant to be an individual control (e.g., the investigator can remove subject-tosubject variation). Findings determined that the use of cues resulted in a significant increase in the positive responses in both the face-toface and tele-dysphagia groups, validating not only the use of cues to improve positive outcomes, but also to validate tele-dysphagia as an alternate service mode. 
Evidence contributing to the reliability of this investigation, thus far, is limited solely to the results of this study as demonstrated by results from the mixed-design analysis of variance. For example, the between-subject effect demonstrates no significant main effects with regard to gender, delivery type, etiology, or age, which offers some evidence of reliability; however, this study would need to be repeated with additional groups in order to truly substantiate this claim.

Effectiveness was additionally demonstrated during a comparison of clinical goal achievement in both groups, with the tele-dysphagia group achieving slightly higher outcomes ( $87 \%$ of tele-dysphagia participants versus $80 \%$ of face-to-face participants). One could therefore conclude that the tele-dysphagia mode of intervention is as effective as the faceto-face mode given a standard dysphagia intervention goal [10].

\section{Study limitations}

The fact that the principal investigator was one of the two clinicians involved in data acquisition may lend itself toward study bias. This was an unforeseen circumstance, due to billing requirements of the medical center / investigation site, which appropriately declined to bill for the dysphagia services provided during this study. Subsequently, the attending speech-language pathologist was periodically unavailable to participate in this investigation. Having an additional certified clinician analyze all trials for inter-rater reliability served as an attempt to minimize study bias.

It is important to note that a crucial element of successful teledysphagia is the presence of an additional individual at the participant site to troubleshoot issues with the telepractice equipment and ensure participant safety. Although detailed safety precautions were employed for this investigation, it may be difficult for dysphagia practitioners to generalize or establish the same degree of safety for their patients. Additionally, this investigation was limited to a primary medical diagnosis of either CVA or TBI, which limits generalization of findings to these populations.

Participants in a tele-dysphagia mode of service delivery can only interact in visual and auditory modes. Since face-to-face dysphagia assessment and intervention frequently incorporate tactile observations [37], current intervention practices via tele-dysphagia would need to be limited to visual and auditory observations and interactions, which could potentially influence outcomes negatively. For example, certain strategies, such as the double swallow strategy [33] or a prep set strategy [33] were not chosen for this study given that participant responses may not be accurately perceived via video / audio alone. Subsequently, this may limit current tele-dysphagia intervention sessions to those that only require visual and auditory observations, though one cannot exclude that future advances in technology may allow for monitoring of tactile input.

\section{Conclusion}

This investigation was proposed and initiated because a review of the literature has established two primary considerations: a clearly defined need for tele-dysphagia services given projected geriatric and dysphagic population trends; and, limited research determining the reliability, validity and effectiveness of tele-dysphagia intervention. Although the results of this investigation profess to expand upon the current knowledge base by validating the use of tele-dysphagia for intervention, future studies should ideally feature a larger sample size and target a greater variety of populations in order to allow for a greater generalization of information. Further, outcomes regarding the type of swallowing strategy selected could be studied. As outlined above, another consideration for future research would be the investigation of improved audio and visual signals during tele-dysphagia sessions, as well as an investigation of the potential for the immediate transfer of tactile input, since palpation of the larynx features prominently in face-to-face dysphagia assessment and intervention [33]. This could potentially allow for a more comprehensive assessment, as well as for the instruction and monitoring of a greater number of safety strategies.

\section{References}

1. Edwards M, Stredler-Brown A, Houston KT (2012) Expanding use of telepractice in speech-language pathology and audiology. Volta Review 112: 227-242. [Crossref]

2. Khan A, Carmona R, Traube M (2014) Dysphagia in the elderly. Clin Geriatr Med 30: 43-53. [Crossref]

3. Coyle J (2012) Tele-dysphagia management: An opportunity for prevention, costsavings, and advanced training. Int $J$ Telerehabil 4: 37-40. [Crossref]

4. American Speech-Language-Hearing Association (2005) Speech-language pathologists providing clinical services via telepractice: Technical report. Rockville, USA.

5. American Speech-Language-Hearing Association (2015) Rockville, Telepractice overview, USA

6. Baharav E, Reiser C (2010) Using telepractice in parent training in early autism. Telemed J E Health 16: 727-731. [Crossref]

7. Brennan DM, Georgeadis AC, Baron CR, Barker LM (2004) The effect of videoconference-based telerehab on story retelling performance by brain injured subjects and its implication for remote speech-language therapy. Telemed $J$ E Health 10: 147-154. [Crossref]

8. Carey B, O'Brian S, Onslow M, Packman A, Menzies R (2012) Webcam delivery of the Camperdown Program for adolescents who stutter: A phase I trial. Lang Speech Hear Serv Sch 43: 370-380. [Crossref]

9. Gabel R, Grogan-Johnson S, Alvares R, Bechstein L, Taylor J (2013) A field study of telepractice for school intervention using the ASHA NOMS K-12 database. Commun Disord Q 35: 44-53.

10. Grogan-Johnson S, Alvares R, Rowan L, Craighead N (2010) A pilot study comparing the effectiveness of speech language therapy provided by telemedicine with conventional on-site therapy. J Telemed Telecare 16: 134-139. [Crossref]

11. Grogan-Johnson S, Schmidt AM, Schenker J, Alvares R, Rowan LE, et al (2013) A comparison of speech sound intervention delivered by telepractice and side-by-side service delivery models. Commun Disord Q 34: 210-220. [Crossref]

12. Hall N, Boisvert M, Steele R (2013) Telepractice in the assessment and treatment of individuals with aphasia: a systematic review. Int $J$ Telerehabil 5: 27-38. [Crossref]

13. Lewis C, Packman A, Onslow M, Simpson J, Jones M (2008) A Phase II trial of telehealth delivery of the Lidcombe Program of Early Stuttering Intervention. Am J Speech Lang Pathol 17: 139-149. [Crossref]

14. Scheideman-Miller C, Clark PG, Smeltzer SS, Carpenter J, Hodge B, et al. (2002) Two year results of a pilot study delivering speech therapy to students in a rural Oklahoma school via telemedicine.

15. Waite M, Theodoros D, Russel T, Cahill L (2010) Internet-based telehealth assessmen of language using the CELF-4. Lang Speech Hear Serv Sch 41: 445-458. [Crossref]

16. Crutchley S, Campbell M (2010) Telespeech therapy pilot project: Stakeholder satisfaction. Int $J$ Telerehabil 2: 23. [Crossref]

17. McCullough A (2001) Viability and effectiveness of teletherapy for pre-school children with special needs. Int J Lang Commun Disord 36: 321-326. [Crossref]

18. Malandraki GA, McCullough G, McWeeny E, He X, Perlman A (2011) Teledynamic evaluation of oropharyngeal swallowing. J Speech Lang Hear Res 54: 1485-1505. [Crossref]

19. Malandraki GA, Markaki V, Georgopoulous VC, Bauer KL, Kalogeropoulous I, et al. (2013) An international pilot study of asynchronous teleconsultation for oropharyngeal dysphagia. J Telemed Telecare 19: 75-79. [Crossref]

20. Ward E, Crombie J, Trickey M, Hill A, Theodoros D, et al (2009) Assessment of communication and swallowing post-laryngectomy: a telerehabilitation trial. $J$ Telemed Telecare 15: 232-237. [Crossref]

21. Ward EC, Burns CL, Theodoros DG, Russell TG (2014) Impact of dysphagia severity on clinical decision making via telerehabilitation. Telemed J E Health 20: 296-303. [Crossref] 
22. Malandraki GA, Roth M, Sheppard JJ (2014) Telepractice for pediatric Dysphagia: a case study. Int J Telerehabil 6: 3-16. [Crossref]

23. Sharma S, Ward EC, Burns C, Theodoros D, Russell T (2011) Assessing swallowing disorders online: a pilot telerehabilitation study. Telemed J E Health 17: 688-695. [Crossref]

24. Ward EC, Sharma S, Burns C, Theodoros D, Russell T (2012) Validity of conducting clinical dysphagia assessments for patients with normal to mild cognitive impairment via telerehabilitation. Dysphagia 27: 460-472. [Crossref]

25. Burns C, Ward E, Hill A, Phillips N, Porter L (2015) Conducting real-time videofluoroscopic swallow study via telepractice: A preliminary feasibility and reliability study. Dysphagia 31: 473-483. [Crossref]

26. Perlman AL, Witthawaskul W (2002) Real-time remote telefluoroscopic assessment of patients with dysphagia. Dysphagia 17: 162-167. [Crossref]

27. Burns CL, Ward EC, Hill AJ, Malcolm, K, Bassett L, Kenny LM, Greenup P (2012) A pilot trial of a speech pathology telehealth service for head and neck cancer patients. $J$ Telemed Telecare 18: 443-446. [Crossref]

28. Burns CL, Ward EC, Hill AJ, Kularatna S, Byrnes J, Kenny LM (2017) Randomized controlled trial of a multisite speech pathology telepractice service providing swallowing and communication intervention to patients with head and neck cancer: Evaluation of service outcomes. Head Neck 39: 932-939. [Crossref]
29. Marinschek S, Dunitz-Scheer M, Pahsini K, Geher B, Scheer P (2014) Weaning children off enteral nutrition by netcoaching versus onsite treatment: A comparative study. J Paediatr Child Health 50: 902-907. [Crossref]

30. Wall L, Ward C, Cartmill B, Hill A, Porceddu S (2015) Examining user perceptions of SwallowIT:A pilot study of a new telepractice application for delivering intensive swallowing therapy to head and neck cancer patients. J Telemed Telecare: 53-59. [Crossref]

31. Wall L, Ward C, Cartmill B, Hill A, Porceddu S (2017) Adherence to a prophylactic swallowing therapy program during (chemo) radiotherapy: Impact of service-delivery model and patient factors. Dysphagia 32: 279-292. [Crossref]

32. Robbins J, Hind J (2008) Overview of Results From the Largest Clinical Trial for Dysphagia Efficacy Treatment.

33. Logemann JA (1998) The evaluation and treatment of swallowing disorders. Curr Opin Otolaryngol Head Neck Surg 6: 395-400.

34. American Speech-Language-Hearing Association (2002) Survey of telepractice use among audiologists and speech-language pathologists. Rockville, USA.

35. VSee (2015)

36. Cohen J (1960) A coefficient of agreement for nominal scales. Educ Psychol Meas 20: $37-46$.

37. Swigert NB (2000) The Source for Dysphagia. LinguiSystems. Texas, USA.

Copyright: (2017 Cassel SG.This is an open-access article distributed under the terms of the Creative Commons Attribution License, which permits unrestricted use, distribution, and reproduction in any medium, provided the original author and source are credited. 